\title{
Drug design based on the principle of conjunction: synthesis, characterization and antihyperglycemic activity study of 3- [2- (3- aroyl- 2, 4- diphenyl- 3 , 4- dihydro- $2 \mathrm{~h}[1,3]$ oxazino [5, 6-h] quinolin- 6- yl) ethyl] 2- phenyl- quinazolin- 4(3h)- ones
}

Bishnoi A., Awasthi R., Pandey V.K., Tiwari A.K., Awasthi N.K., Srivastava K. and Singh S.* *Department of Chemistry, Lucknow University, Lucknow-226007, India, suruchi.singh19@gmail.com

\begin{abstract}
Reaction of anthranilic acid with an excess equivalent of benzoyl chloride in dry pyridine afforded 2- phenyl- $4 \mathrm{H}$ - benzo [d] [1,3] oxazin- 4- one (I) which on reaction with $\beta$-aminoethanol (cholamine) in pyridine solvent yielded 3- (2- hydroxyethyl) - 2- phenylquinazolin- 4(3H)- one (II). When (II) was reacted with 8-hydroxyquinoline (oxine) in conc. $\mathrm{H} 2 \mathrm{SO} 4$, 3- [2- (8- hydroxy- quinolin- 5- yl) ethyl] 2- phenylquinazolin - 4(3H)- one (III) was obtained which on reaction with primary aromatic amines and excess of aromatic aldehydes furnished 3- [2- (3- benzoyl- 2, 4- diphenyl- 3, 4- dihydro- 2H- [1, 3] oxazino [5, 6-h] quinazolin- 6yl) ethyl- 2- phenyl- quinazolin - $\mathrm{H}(3 \mathrm{H})$ - ones (IV). The target compounds (IV) and the intermediates (III) were evaluated for their antihyperglycemic activity in sucrose loaded rat models.
\end{abstract}

Keywords- Anthranilic acid, Benzoyl chloride, Pharmacophoric moieties Quinazolinones, Diabetes mellitus, Antihyperglycemic activity

\section{Introduction}

Literature survey reveals that quinoline and quinazolone derivatives have been less extensively investigated in diabetes mellitus. One research report for quinoline- 8- acyl- sulphonyl ureas is available showing good antihyperglycemic activity in rabbits [1]. In the same manner one compound of the quinazolone series viz; 2- piperazino- 4- quinazolone had hypoglycemic activity in some animal models but not others. No explanation was offered regarding the mechanism of action [2,3]. Currently, it is believed that this compound stimulates insulin release from the pancreas [4]. Quinoline, quinazolone and oxazine compounds are associated with several biological properties and therefore it was thought to unite the three pharmacologically active nuclei in one molecular union for improved therapeutic results. This approach called drug design through conjunction involves the principle of mixed moieties, i.e., a drug molecule is essentially made up with two or more pharmacophoric moieties embedded in a single molecule $[5,7]$.

\section{Experimental procedure}

2- Phenyl- 4H- benzo [d] [1, 3] oxazin- 4- one (I) and 3- (2- hydroxy- ethyl) - 2- phenylquinazolin$4(3 \mathrm{H})$ one $(\mathrm{I})$ were synthesized following the literature methods $5,7$.

\section{3- [2- (8- Hydroxy- Quinolin- 5- YI) Ethyl] 2- Phenylquinazolin- 4(3h) - One (III) \\ 3- (2- Hydroxyethyl) - 2- phenylquinazolin- $4(3 \mathrm{H})$ - one (II) (0.02 mole) and $\beta$ - aminoethanol (0.02 mole) were dissolved in conc. $\mathrm{H} 2 \mathrm{SO} 4$ by stirring cautiously and cooling occasionally. Complete dissolution of the reactants required 30 minutes. Subsequently, the dark coloured solution was stirred mechanically for one hour and the acidified solution was left under refrigeration. Pouring the acidified solution in ice-cold water}

resulted in solidification and allowed to settle down. The solid phase was filtered off and washed with cold water. It was dried and recrystallized from ethanol. It was obtained as a pale yellow crystalline solid which melted at 280 - 281 ${ }^{\circ} \mathrm{C}$, yield, $70 \%$. Analysis for $\mathrm{C} 25 \mathrm{H} 19 \mathrm{~N} 3 \mathrm{O} 2$ : $\mathrm{N}$ calcd. $10.63 \%$; found, $10.25 \%$.

3- [2- (AROYL- 2, 4- DIPHNEYL- 3, 4DIHYDRO- 2H-[1, 3] OXAZINO [5, 6-H] QUINOLIN- 6-YL) ETHYL] 2- PHENYLQUINAZOLIN- 4(3H) ONES (IV)

A mixture consisting of 3- [2- (8- hydroxy quinolin- 5- yl) ethyl] 2- phenyl quinazolin- $4(3 \mathrm{H})$ one (III) (0.01 mole) an aromatic primary amide (0.01 mole) and an aromatic aldehyde (0.02 mole) in absolute ethanol $(50 \mathrm{ml})$ was heated under reflux under anhydrous conditions of the reaction for $6 \mathrm{hrs}$. Ethanol was distilled off and the residual pasty mass was triturated with petroleum ether (b. p. $60-80^{\circ} \mathrm{C}$ ) followed by washing with a $5 \%$ solution of sodium carbonate. Finally, the crude material was washed at $100^{\circ} \mathrm{C}$. The crude compound was recrystallized from benzene. Target compounds thus synthesized, are presented in Table-I alongwith their characterization data.

\section{Biological activity Antihyperglycemic activity \\ Effect of investigational compounds on sucrose tolerance test in normoglycemic rats i.e., effect on sucrose loaded rat model [8.9]. \\ Method and Materials \\ Male albino rats of Wistar strain were selected for this study. Fasting blood glucose level of each animal was checked by glucometer using glucostirps after an overnight starvation. Animals showing blood glucose level between 60 and 80}


$\mathrm{mg} / \mathrm{dl}$ at 0 minute were finally selected and divided in groups of five animals in each. Rats of experimental group were administered the suspension of test samples orally prepared in $1.0 \%$ gum acacia (vehicle) at desired dose levels i.e. $100 \mathrm{mg} / \mathrm{kg}$ in case of standard antidiabetic drug, i.e., metformin. Animals of control group were given an equal amount of $1.0 \%$ gum acacia. An oral sucrose load of $10 \mathrm{~g} / \mathrm{kg}$ body weight was always given 30 minutes post administration of test sample/ vehicle. Blood glucose profile of each rat was again determined at $30,60,90$, and 120 minutes post administration of sucrose by glucostirps. Food, but not water, was withheld from the cages during the course of experimentations.

\section{Statistical Analysis}

Quantitative glucose tolerance of each animal was calculated by Area Under Curve (AUC) method using prism software. Comparing the AUC of experimental and control groups determined the percentage antihyperglycemic activity. Statistical comparison was made by Dunnett's test. Results are expressed as mean \pm SEM. The antihyperglycemic activity data are recorded in Table-ll.

\section{Results and Discussion}

The entire four compounds (three target compounds and one intermediate) were found to show the comparable antihyperglycemic activity in sucrose challenged rat models. It is evident from the biological activity data recorded in Table II that the phenyl substituted compound (compound no. 1) showed percent antihyperglycemic activity to the extent of 22.20 while a nicotinamido substituted compound (compound no. 3) showed 1\% decreased antihyperglycemic activity. The intermediate compound and the compound no. 2 showed equal magnitude of antihyperglycemic activity. It is inferred here that substituents have little effects in such compounds.

\section{Acknowledgement}

The authors are thankful to the head, Chemistry department, Lucknow University, Lucknow for providing necessary laboratory facilities and to the Director, CDRI, Lucknow for providing elemental, spectral and biological activity data.

\section{References}

[1] Weyer R., Aumuller W., Bander A., Hcerdt R., Pfaff W., Schweitzer R. and Weber H. (1974) Arzneim Forsch, 24, 269.

[2] Gupta C.M., Bhaduri A.P., Khanna N.M. and Mukherjee S.K. (1971) Ind. J. Chem., 9, 201.

[3] Mukherjee S. K. (1973) Biochem. Pharmacol., 22, 1529.

[4] Mukherjee S.S., Murthi P.S.R. and Mukherjee S.K. (1976) Acta Diabet. Lat., 13, 8.

[5] Pandey V.K. (1978) Acta Ciencia Indica, 4, $230-235$.

[6] Pandey V.K., Pathak L.P. and Mishra S.K. (2005) Ind. J. Chem., 44, 1940 - 1943.

[7] Pandey V.K., Mishra D., Joshi M.N. and Chandra K. (1988) Pharm. Res. Commun., 20, $153-165$.

[8] Nelson N. (1944) J. Biol. Chem., 153, 375.

[9] Pathak L.P., Shukla R., Pandey V.K. and Tusi S. (2008) Ind. J. Het. Chem., 17, $373-374$. 


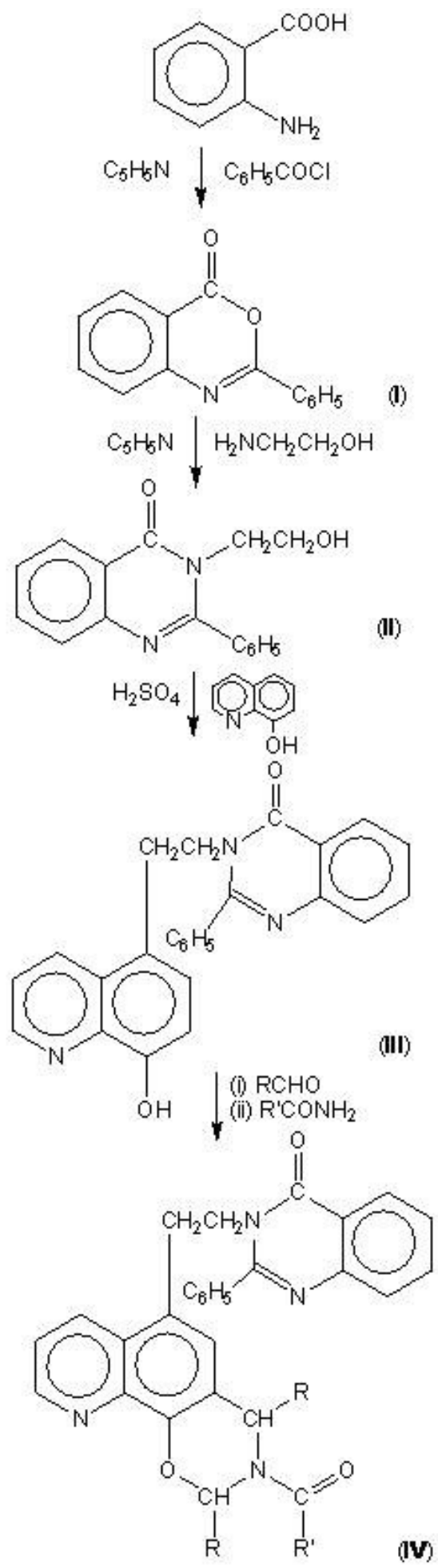

SCHEME 
Drug design based on the principle of conjunction: synthesis, characterization and antihyperglycemic activity study of 3- [2- (3- aroyl- 2, 4- diphenyl- 3 , 4- dihydro- $2 \mathrm{~h}[1,3]$ oxazino [5, 6-h] quinolin- 6 - yl) ethyl] 2- phenyl- quinazolin- 4(3h)- ones

Table I- Characterization data of 3- [2- (3- aroyl-2, 4- diphenyl- 3, 4- dihydro- 2H [1, 3] oxazino [5, 6-h] quinolin- 6-yl) ethyl] 2-phenyl quinazolin- 4 (3H) ones (IV)

\begin{tabular}{|c|c|c|c|c|c|c|c|}
\hline \multirow{2}{*}{$\begin{array}{l}\text { Compound } \\
\text { No. }\end{array}$} & \multirow[t]{2}{*}{$\mathbf{R}$} & \multirow[t]{2}{*}{$\mathbf{R}^{\prime}$} & \multirow[t]{2}{*}{ m.p. $\left({ }^{\circ} \mathrm{C}\right)$} & \multirow[t]{2}{*}{ Yield } & \multirow{2}{*}{$\begin{array}{l}\text { Molecular } \\
\text { Formula }\end{array}$} & \multicolumn{2}{|c|}{ Analysis Nitrogen \% } \\
\hline & & & & & & Calcd. & Found \\
\hline 1 & $\mathrm{C} 6 \mathrm{H} 5$ & $\mathrm{C} 6 \mathrm{H} 5$ & $280-281$ & 72 & $\mathrm{C} 46 \mathrm{H} 34 \mathrm{~N} 4 \mathrm{O} 3$ & 8.11 & 7.96 \\
\hline 2 & $\mathrm{C} 6 \mathrm{H} 5$ & 2-OH.C6H4 & $275-276$ & 74 & $\mathrm{C} 46 \mathrm{H} 34 \mathrm{~N} 4 \mathrm{O} 6$ & 7.92 & 7.77 \\
\hline 3 & $\mathrm{C} 6 \mathrm{H} 5$ & $3-\mathrm{C} 5 \mathrm{H} 4 \mathrm{~N}$ & $230-231$ & 76 & $\mathrm{C} 45 \mathrm{H} 33 \mathrm{~N} 3 \mathrm{O} 3$ & 6.33 & 6.34 \\
\hline
\end{tabular}

$\mathrm{IR}(\mathrm{KBr})\left(\sqrt{\mathrm{cm}^{-1}}\right): 1625(\mathrm{C}=\mathrm{N}), 1647$ (tert. amide $\left.\mathrm{C}=\mathrm{O}\right), 1047(\mathrm{ArOCHAr}), 1602,1553,1451(\mathrm{C}=\mathrm{C})$

${ }^{1} \mathrm{HNMR}\left(\mathrm{CDCl}_{3}\right)(\delta \mathrm{ppm}): 6.92-7.98(\mathrm{~m}, 23 \mathrm{H}, \mathrm{Ar} \underline{\mathrm{H}}), 3.76\left(\mathrm{t}, 2 \mathrm{H}, \mathrm{ArC}_{2}, \mathrm{~J}=7.15 \mathrm{cps}\right), 4.87\left(\mathrm{t}, 2 \mathrm{H}, \mathrm{N}-\mathrm{CH}_{2}, \mathrm{~J}=7.15\right.$ cps), $5.08(\mathrm{~s}, 1 \mathrm{H}, \mathrm{Ar}-\mathrm{C} \underline{\mathrm{H}}) 5.42\left(1 \mathrm{H}, \mathrm{O}-\mathrm{C}^{\mathrm{H}} \mathrm{C}_{6} \mathrm{H}_{5}\right)$

Mass: $\mathrm{M}^{+} 692,105$ (base peak)

Table II- Antihyperglycemic activity data of 3- [2- (3- aroyl- 2, 4- diphenyl- 3, 4- dihydro- 2H- [1, 3] oxazino [5, 6-h]

\begin{tabular}{|c|c|c|c|c|c|}
\hline $\begin{array}{l}\text { Compound } \\
\text { No. }\end{array}$ & $\mathbf{R}$ & $\mathbf{R}^{\prime}$ & Model & $\begin{array}{l}\text { Dose } \\
\text { (mg/kg/rat) }\end{array}$ & $\begin{array}{l}\text { Percent } \\
\text { Antihyperglycemic } \\
\text { Activity }\end{array}$ \\
\hline 1 & $\mathrm{C} 6 \mathrm{H} 5$ & $\mathrm{C} 6 \mathrm{H} 5$ & SLM & 100 & 22.2 \\
\hline 2 & C6H5 & $\begin{array}{l}2-\mathrm{OH} . \\
\mathrm{C} 6 \mathrm{H} 4\end{array}$ & SLM & 100 & 20.2 \\
\hline 3 & C6H5 & 3.C5H5N & SLM & 100 & 21.2 \\
\hline $\begin{array}{l}4 \\
\text { (Intermediate } \\
\text { Compound) }\end{array}$ & $\begin{array}{l}\text { 3-[2-(8-Hydroxy-quinolin-5-yl)ethyl]2-phenyl } \\
\text { quinazolin-4(3h)-one }\end{array}$ & - & SLM & 100 & 20.2 \\
\hline
\end{tabular}

